\title{
Angiolymphoid hyperplasia with eosinophilia - A report of three cases
}

\section{Mrinal Gupta}

\author{
Department of Dermatology, Treatwell Skin Centre, Jammu and Kashmir, India
}

Corresponding author: Dr. Mrinal Gupta, E-mail: drmrinalgupta@yahoo.com

\begin{abstract}
Angiolymphoid hyperplasia with eosinophilia (ALHE) is an uncommon, reactive vaso-proliferative disease, presenting with painless, vascular nodules in the dermal and subcutaneous tissues, sually seen in the head and neck region. It is characterized clinically by single to multiple red brown dome shaped papules or subcutaneous nodules. Its etiology is unknown and the histology is characterized by hyperplastic blood vessels lined by a hypertrophic endothelium with an inflammatory infiltrate rich in eosinophils. We report three cases of ALHE presenting over the ears and scalp.
\end{abstract}

Key words: Angiolymphoid hyperplasia with eosinophilia; Eosinophilia; Angioproliferative; Pseudopyogenic granuloma

\section{INTRODUCTION}

Angiolymphoid hyperplasia with eosinophilia (ALHE), also called as atypical or pseudo pyogenic granuloma, is characterized by solitary or multiple red to brown papules or nodules seen commonly in women between 20 and 40 years of age. The etiology of ALHE remains unknown, because it is not clear if it is primarily a vascular neoplasm, a lymphoproliferative process or a heterogeneous group of entities [1]. Trauma, infections and hyperestrogenic conditions (pregnancy or oral contraceptive agents) are considered to be the likely causes. ALHE usually appears in head and neck region, frequently in the auricular area and usually measures about 2-3 $\mathrm{cm}$ in size [2]. ALHE must be histologically and clinically differentiated from Kimura disease, which is a chronic inflammatory condition, characterized by large subcutaneous nodules in the head and neck region [3]. We report three cases of ALHE with characteristic clinical and histological features.

\section{CASE REPORT}

\section{Case 1}

A 45-year old male who presented to us with chief complaints of multiple, asymptomatic, gradually progressive reddish nodular lesions over the back of the head for the last three years. There was history of excessive bleeding from a few lesions even on minor trauma. The patient had consulted some physicians and had applied numerous medications without any relief. The patient had got a few bigger lesions removed surgically one year back, but they had recurred. On examination, there were multiple red, non-pulsatile smooth surfaced papules, over the occipital region (Fig. 1). There was no lymphadenopathy. Other systems were normal. Differential count showed 18\% eosinophils and his $\operatorname{IgE}$ level was normal. An excisional biopsy of the lesions was done which revealed proliferation of small vessels lined by plump endothelial cells, surrounded by inflammatory cells including lymphocytes, mastocytes and eosinophils which confirmed the diagnosis of ALHE (Fig. 2). The bigger lesions were removed by radiofrequency but after a six month follow up, a few lesions had recurred.

\section{Case 2}

A 15 year old male presented to us with history of asymptomatic, gradually progressive nodular lesions over the meatus of the right ear. The lesions started at the age of 11 years and were a single nodule to begin with, but over the time, they had increased in size

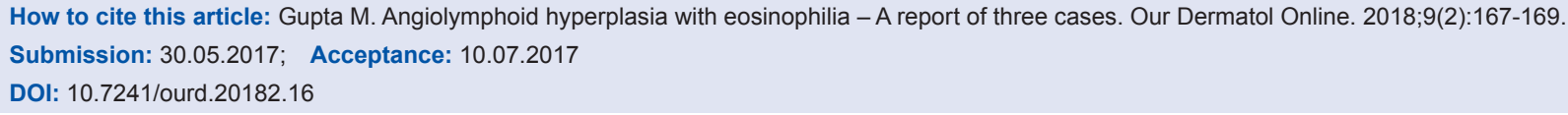




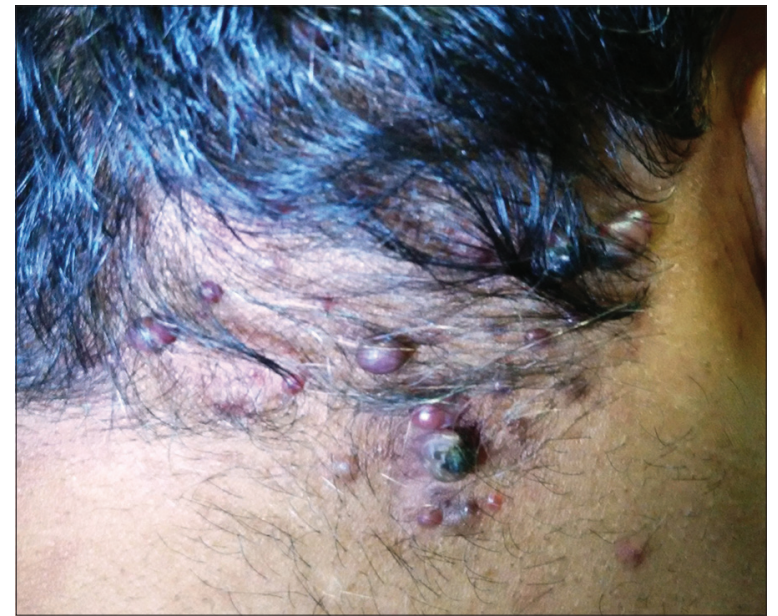

Figure 1 : Multiple reddish nodular lesions on the occipital region.

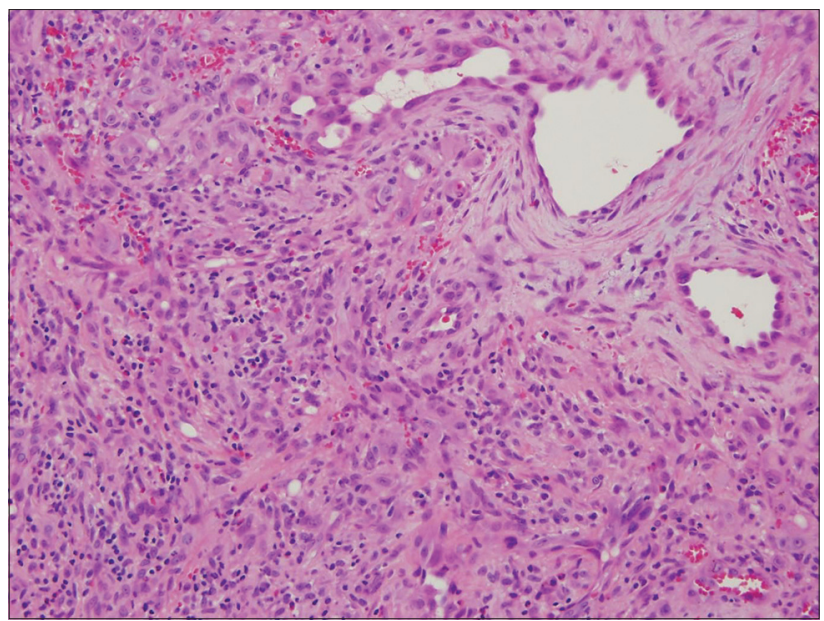

Figure 2: Proliferation of blood vessels in the dermis. The vessels are lined by plump epithelioid endothelial cells with surrounding eosinophilic infiltration.

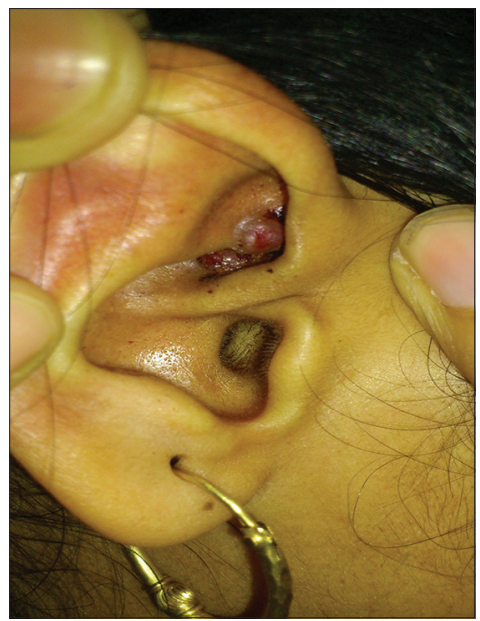

Figure 3: Multiple angiomatous nodules present over the meatus of ear.

and number to their present size, but had remained asymptomatic throughout. On examination, there were multiple red, non-pulsatile smooth surfaced papules, over the pre auricular region extending on to the crus of the helix, and into the meatus of the right ear (Fig. 3). There was no lymphadenopathy. The histology of the lesion was consistent with ALHE. The patient was advised radiofrequency removal of the lesion which was refused by the parents.

\section{Case 3}

A 27-year old female presented with multiple asymptomatic, reddish nodular lesions over the ear for the last four years. Examination revealed multiple red, non-pulsatile smooth surfaced papules, over the pre auricular region. The histology of the lesion confirmed the diagnosis of ALHE. The lesions were removed by radiofrequency and there was no recurrence of the lesions over a three month follow up period.

\section{DISCUSSION}

ALHE, also known as pseudo- or atypical pyogenic granuloma, subcutaneous angioblastic lymphoid hyperplasia with eosinophilia, and papular angioplasia, was first described by Wells and Whimster in 1969, who considered ALHE to be a late stage of Kimura's disease. It is usually seen in the third and fourth decade with a slight female predominance [3]. The pathogenesis of ALHE remains unclear. Some authors consider ALHE as a neoplasm developing from endothelial cells; others suggest that it is secondary to an inflammatory vascular reaction secondary to complex immunologic mechanisms. Many other hypotheses have been reported implicating environmental factors such as insect bite, trauma, and infections. Some authors consider arterio-venous shunt to be the main etiopathogenetic mechanism [3-5]. Cutaneous lesions consist of red papules or persistent subcutaneous nodules which may be associated with spontaneous bleeding, pain, pulsation and pruritus.

The diagnosis is based on clinical features and the histopathology which is characterized by a proliferation of small vessels lined by epithelioid endothelial cells and surrounded by inflammatory cells including lymphocytes, mastocytes and eosinophils. Serum hypereosinophilia is not a consistent feature, seen in around $20 \%$ of cases, and is not required to make the diagnosis. The various differential diagnoses include Kimura's disease, angiomatous neoplasias such as capillary hemangioma, granuloma pyogenicum with 
satellite lesions, angiosarcoma of the face and scalp, and Kaposi sarcoma [2-5].

A variety of treatment modalities have been described for ALHE. Surgical treatment remains the treatment of choice, but recurrences are observed in 30\% of the cases. Other described treatment modalities include electrodessication, cryotherapy, micrographic surgery, systemic corticosteroid treatment, intra-lesional injection of corticosteroids or sclerosing products, topical tacrolimus, imiquimod, phototherapy and alpha-2a interferon $[2,3,5,6]$.

\section{REFERENCES}

1. Karabudak O, Taskapan O, Bozdogan O, and Dogan B. Angiolymphoid hyperplasia with eosinophilia: Atypical appearance in an older patient. Indian J Dermatol. 2008;53:144-5.

2. Zarrin-Khameh N, Spoden JE, Tran RM. Angiolymphoid hyperplasia with eosinophilia associated with pregnancy: A case report and review of the literature. Arch Pathol Lab Med. 2005;129:1168-71.

3. Zaraa I, Mlika M, Chouk S, Chelly I, Mokni M, Zitouna M, et al. Angiolymphoid hyperplasia with eosinophilia: A study of 7 cases. Dermatol Online J. 2011;17:1.

4. Demitsu T, Nagato H, Inoue T. Angiolymphoid hyperplasia with eosinophilia: its character and therapy. Skin Surg. 2000; 9: 8-16.

5. Gupta M. Angiolymphoid hyperplasia with eosinophilia. Our Dermatol Online. 2017;8:94-5.

6. Ramchandani PL, Sabesan T, Hussein K. Angiolymphoid hyperplasia with eosinophilia masquerading as Kimura disease. $\mathrm{Br}$ J Oral Maxillofac Surg. 2005;43:249-52.

Copyright by Mrinal Gupta, et al. This is an open-access article distributed under the terms of the Creative Commons Attribution License, which permits unrestricted use, distribution, and reproduction in any medium, provided the original author and source are credited.

Source of Support: Nil, Conflict of Interest: None declared. 